\title{
Presentación del Tema Central \\ Relaciones de género, sexualidad $y$ salud reproductiva
}

\section{Presentation of Central Theme: \\ Gender relations, sexuality and reproductive bealth}

\author{
Servando Gutiérrez Ramírez \\ Universidad Autónoma Metropolitana Iztapalapa, Ciudad de \\ México, México \\ ORCID: https://orcid.org/oooo-0002-1986-8964 \\ ISSN: ISSN-OI85-4259; e- ISSN: 2007-9176 \\ DoI: http://dx.doi.org/Io.28928/ri/7720I4/ptc/gutierrezramirezs
}

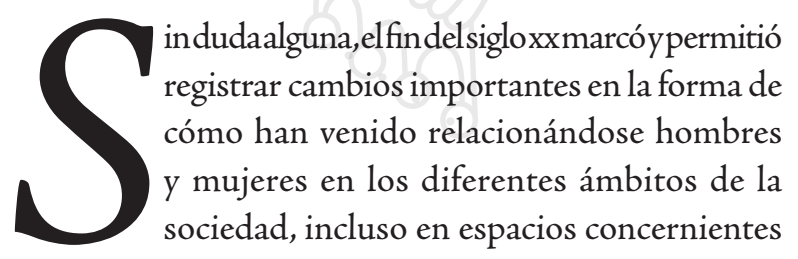
a su individualidad y a su vida privada. Los estudios realizados en el marco de la Teoría del Género -considerada como uno de los más valiosos aportes de la investigación feminista- y lo que se ha producido a partir de la visión de lo que hoy se conoce como masculinidad, han potenciado una visión, una comprensión y una interpretación más holísticas de las transformaciones que ya es posible advertir en el interjuego de roles y comportamientos entre mujeres y hombres en las sociedades consideradas modernas.

Así, temas de singular importancia como el de la equidad de género, o de los derechos sexuales y repro- 
ductivos, se han convertido en referente necesario para identificar con claridad los factores que intervienen, entre otros casos y situaciones, en la violencia que aún se ejerce (en todos sus niveles y facetas) sobre la mujer, en cómo se ha venido generalizando la feminización de la pobreza, así como sus efectos inherentes, y cómo situaciones de esa índole influyen de manera importante en la vivencia y el ejercicio de la vida sexual y reproductiva de la población femenina, y que permite a su vez observar cómo los varones participan ya sea para mantener, reforzar o transformar dichas situaciones.

Incluso, un contexto como el descrito ha llevado a comprender y reflexionar también sobre la forma de cómo los hombres viven y ejercen su sexualidad y su vida reproductiva en un marco de significativas transformaciones familiares, sociales, económicas, políticas y culturales que han venido caracterizando la primera década del nuevo milenio.

Por tanto, en ese marco de referencia y para lo fines del número temático que aquí se presenta, la recuperación de los conceptos de salud, y el de salud sexual y reproductiva, cobran singular relevancia. En este sentido, la salud es entendida como: "un estado de completo bienestar físico, mental y social y no solamente la ausencia de infecciones o enfermedades. El goce del grado máximo de salud que se pueda lograr es uno de los derechos fundamentales de todo ser humano sin distinción de raza, religión, ideología política o condición económica o social”.

Esta definición se complementa con lo señalado en la Declaración Universal de Derechos Humanos que, a la letra, dice en su artículo 25:

I. Toda persona tiene derecho a un nivel de vida adecuado que le asegure, así como a su familia, la salud y bienestar y, en especial, la alimentación, el vestido, la vivienda, la asistencia médica y los servicios sociales necesarios; tiene, asimismo, derecho a los seguros en caso de desempleo, enfermedad, invalidez, viudez, vejez, y otros casos, como pérdida de sus medios de subsistencia por circunstancias independientes de su voluntad. 2. La maternidad y la infancia tienen derecho a cuidados y asistencia especiales.

I La Constitución de la Organización Mundial de la Salud (oms) fue adoptada en Nueva York el 22 de julio de 1946, por la Conferencia Sanitaria Internacional. Fue firmada por los representantes de 6r Estados y entró en vigor el 7 de abril de 1948. Las Reformas adoptadas por la 26. a la 29. ${ }^{\mathrm{a}}$, la $39 .^{\mathrm{a}}$ y la $51{ }^{\mathrm{a}}$ Asambleas Mundiales de la Salud se han incorporado a esta definición. Tales principios fueron reafirmados en la Declaración de Alma-Ata (Conferencia Internacional sobre Atención de Salud Primaria), en 1978. 
Todos los niños, nacidos de matrimonio o fuera de matrimonio, tienen derecho a igual protección social. ${ }^{2}$

Por consiguiente, con base a tales definiciones, la salud es visualizada como uno de los elementos determinantes del desarrollo, y por lo mismo no es casual que, junto con la educación y el ingreso, sea ubicada como uno de los tres componentes del Índice de Desarrollo Humano de las Naciones Unidas.

De igual manera, el Programa de Acción de la ya famosa Conferencia Internacional sobre Población y Desarrollo (CIPD), celebrada en El Cairo, Egipto, en 1994, señala que la salud sexual y reproductiva es:

un estado general de bienestar físico, mental y social, y no de mera ausencia de enfermedades o dolencias, en todos los aspectos relacionados con el sistema reproductivo y sus funciones y procesos. En consecuencia, la salud reproductiva entraña la capacidad de disfrutar de una vida sexual satisfactoria y sin riesgos y de procrear, y la libertad para decidir hacerlo o no hacerlo, cuándo y con qué frecuencia [...] [la atención de la salud reproductiva] incluye también la salud sexual, cuyo objetivo es el desarrollo de la vida y de las relaciones personales y no meramente el asesoramiento y la atención en materia de reproducción y de enfermedades de transmisión sexual. ${ }^{3}$

Por su parte, la Organización Mundial de la Salud, la Organización Panamericana de la Salud y la Asociación Mundial de Sexología, en el año 2000, clarificaron más la definición de salud sexual señalando que esta:

es la experiencia del proceso permanente de consecución de bienestar físico, psicológico y sociocultural relacionado con la sexualidad. La salud sexual se observa en las expresiones libres y responsables de las capacidades sexuales que propician un bienestar armonioso personal y social, enriqueciendo de esta manera la vida individual y social. No se trata simplemente de la ausencia de disfunción o de enfermedad o de ambas. Para que la salud sexual se logre es necesario que los derechos sexuales de las personas se reconozcan y garanticen. ${ }^{4}$

2 Adoptada y proclamada por la Asamblea General en su resolución 217 A (III), del ro de diciembre de 1948 .

3 Capítulo viI, párrafo 7.2., Programa de Acción, Cipd 1994.

4 Organización Mundial de la Salud (2000). Informe sobre la Salud en el Mundo. Mejorar el desempeño de los sistemas de Salud, Ginebra. 
A partir de la recuperación de las definiciones anotadas es posible destacar algunos elementos importantes en la atención de la salud sexual y reproductiva que fueron considerados en la denominada atención primaria de salud y que tienen relación directa con los artículos incluidos en la presente colaboración, los cuales tienen que ver con los aspectos siguientes:

i) la información, educación y comunicación sobre sexualidad humana, salud reproductiva y paternidad responsable; ii) la información y acceso a métodos de planificación familiar que sean apropiados, seguros, efectivos, económicamente accesibles, y aceptados como consecuencia de una decisión informada; iii) la provisión de servicios para un embarazo, parto y puerperio seguros; iv) la generación de mecanismos para la participación comunitaria, en especial de las mujeres, en todos los niveles del sistema de atención a la salud; $v$ ) el que propone alentar la responsabilidad masculina en todos los aspectos vinculados a la salud sexual y reproductiva, brindando especial apoyo al empoderamiento de la mujer en la defensa de sus derechos reproductivos; y vi) el que tiene que ver con el desarrollo de programas innovadores para adolescentes y hombres adultos ${ }^{5}$.

Como puede advertirse, se han destacado los aspectos que señalan y buscan encauzar esfuerzos cada vez más crecientes para involucrar a los varones, adolescentes y adultos, en el cuidado, la responsabilidad y su participación en los aspectos enunciados, así como en que se puedan desarrollar programas específicos en respuesta a necesidades actuales y futuras como las explicitadas en cada uno de los trabajos de investigación aquí presentados; $y$, como se puede observar, no es fortuito que de las cuatro investigaciones, tres aludan precisamente a la participación de adolescentes/jóvenes y varones adultos en tales temáticas.

En este sentido, el trabajo de Elizabeth García: "Embarazo adolescente y pobreza, una relación compleja", inicia con una interesante reflexión acerca de los condicionantes socioeconómicos que, a la par de los socioculturales, pudieran explicar las prácticas sexuales y reproductivas de las mujeres que a tempranas edades experimentan el evento maternidad y que, al parecer, se encuentran "avaladas y reforzadas por el contexto" social de pobreza en el que viven y que se complejiza al abordar circunstancias relacionadas con la alta vulnerabilidad que se experimenta en los ámbitos familiar, escolar y laboral.

Para esta autora existe un acalorado debate en torno a si el embarazo es la causa de la pobreza en que viven las adolescentes y jóvenes, puesto que la correlación entre tener una familia numerosa con bajos ingresos y la falta de apoyo económico de su

5 Tomados del Capítulo viI, párrafos 7.6, 7.7, 7.8, 7.9, 7.II del Programa de Acción, CIPD 1994. 
contraparte masculina parecen indicar que estas mujeres y sus hijos tendrán una alta "probabilidad de vivir en condiciones de precariedad". A esta postura, señala, se contrapone aquella según la cual "las condiciones familiares previas al embarazo, y las escasas oportunidades que les ofrece el contexto, son en realidad la causa de la pobreza y no el embarazo mismo". Por ello, tener un hijo a una edad temprana o tardía no tiene ningún impacto - positivo o negativo- en la situación de pobreza en que viven.

Aunada a lo anterior, la situación familiar de las adolescentes y jóvenes tiene una incidencia por demás relevante pues al provenir ya sea de un ámbito familiar desestructurado y conflictivo o bien de uno donde exista la comunicación armónica entre padres e hijos; esa situación influirá en la aparición o no del embarazo a una edad temprana.

De igual modo, afirma que la escuela y el trabajo (entendido este último como la participación de la mujer en el mercado laboral), en contextos de alta vulnerabilidad económica y social, también ejercen un efecto no tan positivo para revertir su situación de precariedad personal y familiar. Por ejemplo, la escuela, de acuerdo con la autora, "da a los alumnos tratos diferenciales según sus distintos orígenes culturales y socioeconómicos" y, en consecuencia, en buena parte de los casos, segrega y excluye de los beneficios que debieran proporcionar la asistencia y culminación de los diversos niveles educativos a quienes transitan por dicho proceso de habilitación escolar.

El embarazo temprano y, en dado caso, su término -truncado el nivel de escolaridad respectivo- lleva a la adolescente a enfrentarse, en franca desventaja, al mundo laboral, pues su escasa formación implica tener "pocas posibilidades de elección" de trabajos favorables y la sitúan en una pesada responsabilidad de atender los quehaceres y actividades de una persona adulta.

El segundo artículo, el trabajo de Juan Guillermo Figueroa: "Algunas propuestas dialógicas para relacionar paternidad, salud y mortalidad", es una reflexión por demás provocadora - en el mejor de los sentidos- pues, como lo señala el autor, es una manera de cuestionar en forma propositiva conceptos, definiciones y categorías que ciertos campos del conocimiento, como el demográfico o el médico, parecieran dar como inamovibles. Por consiguiente, hablar de "derechos reproductivos de los varones," "mortalidad paterna","salud paterna" o "paternidad sin riesgos" han generado una reacción que ha ido desde la incredulidad hasta la más clara resistencia a aceptar tales consideraciones y lo que pudieran significar.

Figueroa advierte que por sus propios intereses al investigar en la materia, él ha intentado vincular los comportamientos reproductivos y la salud en el ámbito de 
la vivencia y el ejercicio, en este caso de los varones, como un actor fundamental en tales espacios, pero sin perder la referencia de todo lo que se ha escrito para el caso de las mujeres y donde suele considerarse a los varones como "variables" secundarias o no existentes.

En consecuencia, Figueroa, desde el 2000 a fecha, ha encaminado sus trabajos a profundizar en lo que los varones han perdido en su experiencia de vida como tales y no se diga en el ámbito de la reproducción biológica y de la vivencia de la paternidad derivada de ella "por el hecho de no cuestionar modelos de masculinidad dominantes" en sociedades aún conservadoras como la mexicana. Por lo mismo, de acuerdo con el argumento del autor, el que los varones expresen miedos, tensiones, soledad, estrés, y el pensar que tales factores pusieran en riesgo su vida por su forma de vivir su paternidad, no son aspectos que tengan cabida en los modelos tradicionales y dominantes de masculinidad imperantes aún en sociedades aparentemente modernas.

En contrapartida al artículo anterior, en el trabajo "Los hombres mexicanos y el uso de la anticoncepción” Olga Lorena Rojas discute si “realmente los hombres mexicanos se han mantenido al margen de las decisiones reproductivas y anticonceptivas de las parejas" teniendo en consideración que desde sus inicios en los años setenta, los programas institucionales de planificación familiar en el país se han orientado fundamentalmente hacia las mujeres y han dejado de lado o no han considerado prioritaria la participación de los varones.

Tal situación, basada en la idea aún presente en buena parte de la población mexicana de que la responsabilidad de la reproducción biológica y su regulación corresponde a la mujer, ha generado que los varones se vean y se sientan únicamente espectadores del evento reproductivo y un tanto ajenos a la responsabilidad que implica compartirla con su pareja. Esa perspectiva masculina, de acuerdo con Rojas, ha "contribuido a reproducir la desigualdad en las responsabilidades reproductivas entre hombres y mujeres".

Como se anotó al inicio de esta presentación, Rojas coincide con la relevancia que tuvo en su momento la Conferencia Internacional sobre Población y Desarrollo (CIPD) de 1994, en la cual "se planteó la necesidad de realizar esfuerzos para propiciar una responsabilidad compartida de los varones y promover su involucramiento de una manera más activa en una paternidad responsable y en un comportamiento sexual y reproductivo también responsable".

Asimismo, derivado del pronunciamiento de la CIPD, Rojas subraya que en el ámbito de la salud es de suma importancia analizar la vivencia y el ejercicio de la sexualidad y la vida reproductiva de mujeres y hombres, aspectos fundamentales, 
desde la perspectiva o el enfoque de género, pues ello posibilitó contar con un cuerpo teórico para analizar símbolos, prácticas, significados, representaciones, instituciones y normas que las sociedades, las comunidades y las personas elaboran a partir de las diferencias biológicas.

Con base en lo anterior podemos decir, con Rojas -incluso aludiendo a los cuatro trabajos de investigación que forman parte de este número temático-, que la pertinencia de este enfoque es que pone en evidencia las jerarquías de género expresadas en una valoración desigual de lo masculino y lo femenino, una diferencia en la distribución de poder, recursos y oportunidades entre hombres y mujeres y sus consecuencias en materia de vulnerabilidad, exclusión o discriminación en contextos como los presentados en las cuatro investigaciones aquí reunidas.

Un último artículo, que aborda lo concerniente a sexualidad y salud reproductiva de adolescentes y jóvenes, pero en este caso de varones, es el que presentan David Ramírez, Servando Gutiérrez y Clara Elena Valladares: "Masculinidades juveniles en transición a través del preservativo: comparación de dos contextos latinoamericanos". Al tomar como referencia dos poblaciones de adolescentes y jóvenes varones de Quito, y de la región otomí-tepehua del estado de Hidalgo, los autores señalan la posibilidad de advertir que estos adolescentes y jóvenes atraviesan por una "transición cultural" respecto de lo que entienden por masculinidad y cómo la viven.

El conocimiento sobre el uso de un método de anticoncepción y de protección como el preservativo se significó, señalan Ramírez, Gutiérrez y Valladares, como ese factor que ha llevado a los jóvenes quiteños e hidalguenses a reconceptualizar su idea de masculinidad como la forma de ser hombres en un contexto social y cultural característico de la región, en su país respectivo, y que al parecer está ocurriendo un cambio por demás positivo puesto que se pudo detectar una mayor participación de los varones entrevistados en su manera de vivir y ejercer las decisiones sexuales y reproductivas.

En la mayoría de ellos -reportan los autores- existe una percepción de ser más responsables en cuanto al cuidado de la pareja, ya sea para evitar la transmisión de infecciones sexuales y, sobre todo, embarazos no deseados ni planificados en edades tempranas de su vida. Por tanto, concluyen que la mayor disposición de los varones por cuidar no solamente su salud, sino también la de su pareja, es muestra clara de una importante transformación cultural entre los jóvenes del sur de Quito y de la región Otomí-Tepehua, en su manera de "ser hombres" en los tiempos actuales.

Finalmente, y para dejar que los lectores terminen de descubrir la pertinencia de argumentos con los cuales Figueroa termina su artículo, baste recuperar tres sugerentes ideas vertidas por el autor: hablar de "mortalidad paterna" o "paternidad 
sin riesgos" es asociar estas con "conductas autodestructivas y al uso de la violencia como expresión de frustraciones, temores, o... una forma tosca de manifestar sentimientos como tristeza, desesperación y otras conductas asociadas a malestares explícitos o no, derivados de la dificultad para ejercer lo que socialmente se espera de su paternidad"; por lo mismo, se requiere contar con "referencias teóricas y políticas para dar cuenta de casos de pérdida de salud y bienestar por la forma violenta, desgastada, aislada o incompleta en la que se aprende a vivir la paternidad". Reconocer los dos aspectos anteriores permitirá "la construcción de las condiciones de posibilidad para el ejercicio del derecho a la salud y de la integralidad corporal en los mismos hombres".

Estoy seguro de que tal como me ocurrió, disfrutarán la lectura de los cuatro trabajos de investigación ejes del número temático de esta ocasión. 